Supplement of Atmos. Chem. Phys., 16, 6913-6929, 2016

http://www.atmos-chem-phys.net/16/6913/2016/

doi:10.5194/acp-16-6913-2016-supplement

(C) Author(s) 2016. CC Attribution 3.0 License.

(c) (i)

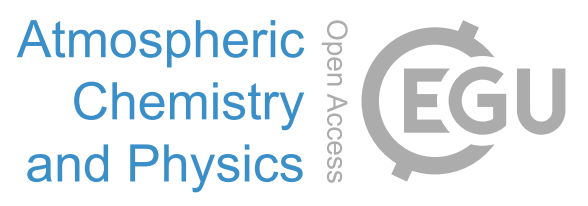

Supplement of

\title{
Diurnal variation of tropospheric relative humidity in tropical regions
}

Isaac Moradi et al.

Correspondence to: Isaac Moradi (isaac.moradi@nasa.gov)

The copyright of individual parts of the supplement might differ from the CC-BY 3.0 licence. 


\section{RH Spatial Distribution}

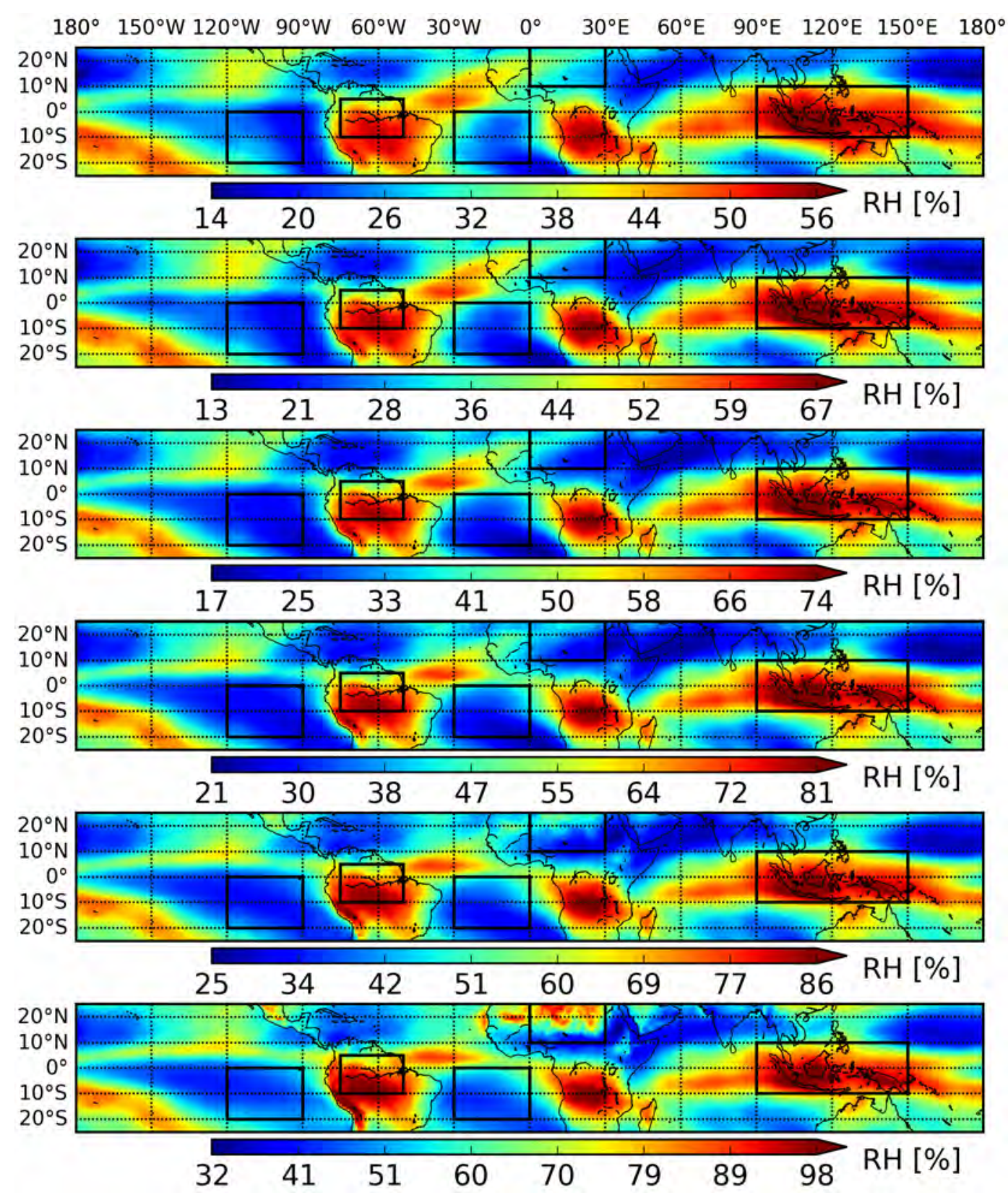

Figure 1. Spatial distribution of layer-averaged $\mathrm{RH}_{I}$ derived using SAPHIR data for December and January. Depicts from top to bottom are for SAPHIR channels 1-6, respectively. 


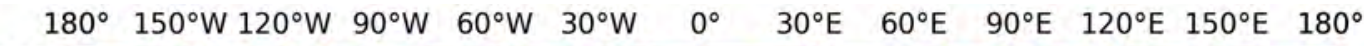
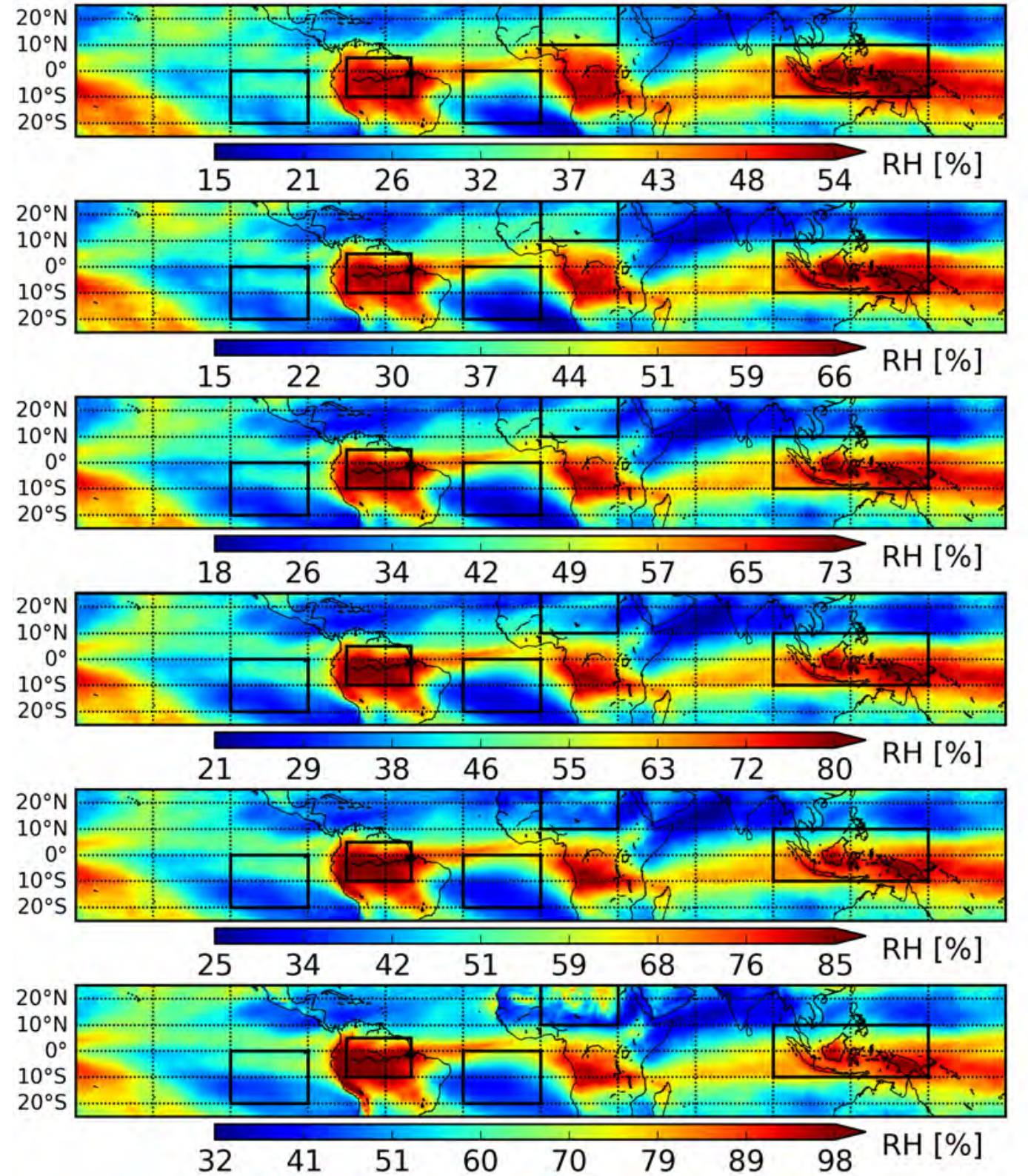

Figure 2. Spatial distribution of layer-averaged $\mathrm{RH}_{I}$ derived using SAPHIR data for the Month March. Depicts from top to bottom are for SAPHIR channels 1-6, respectively. 


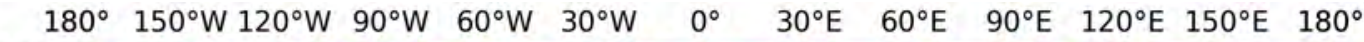
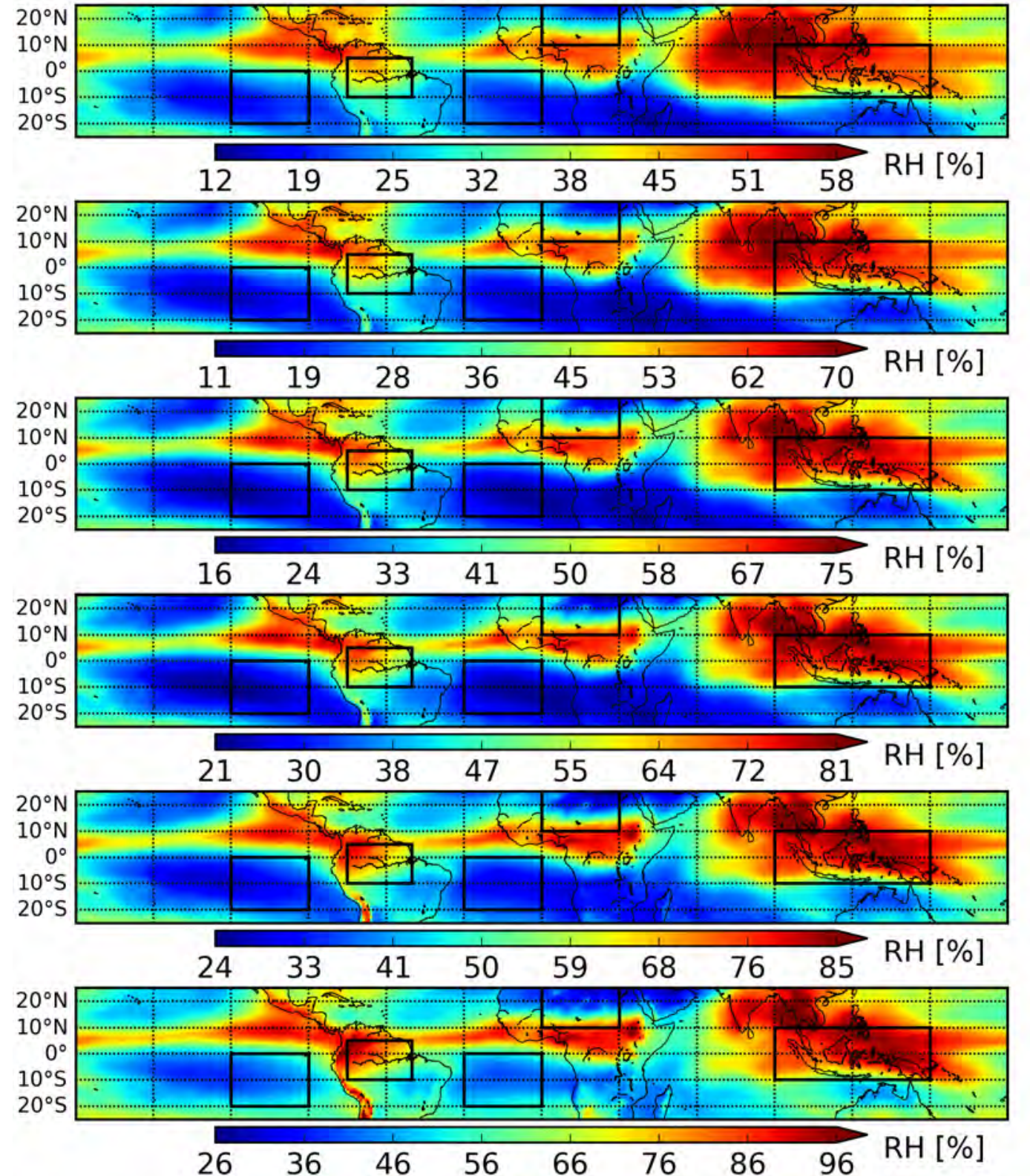

Figure 3. Spatial distribution of layer-averaged $\mathrm{RH}_{I}$ derived using SAPHIR data for June and July. Depicts from top to bottom are for SAPHIR channels 1-6, respectively. 

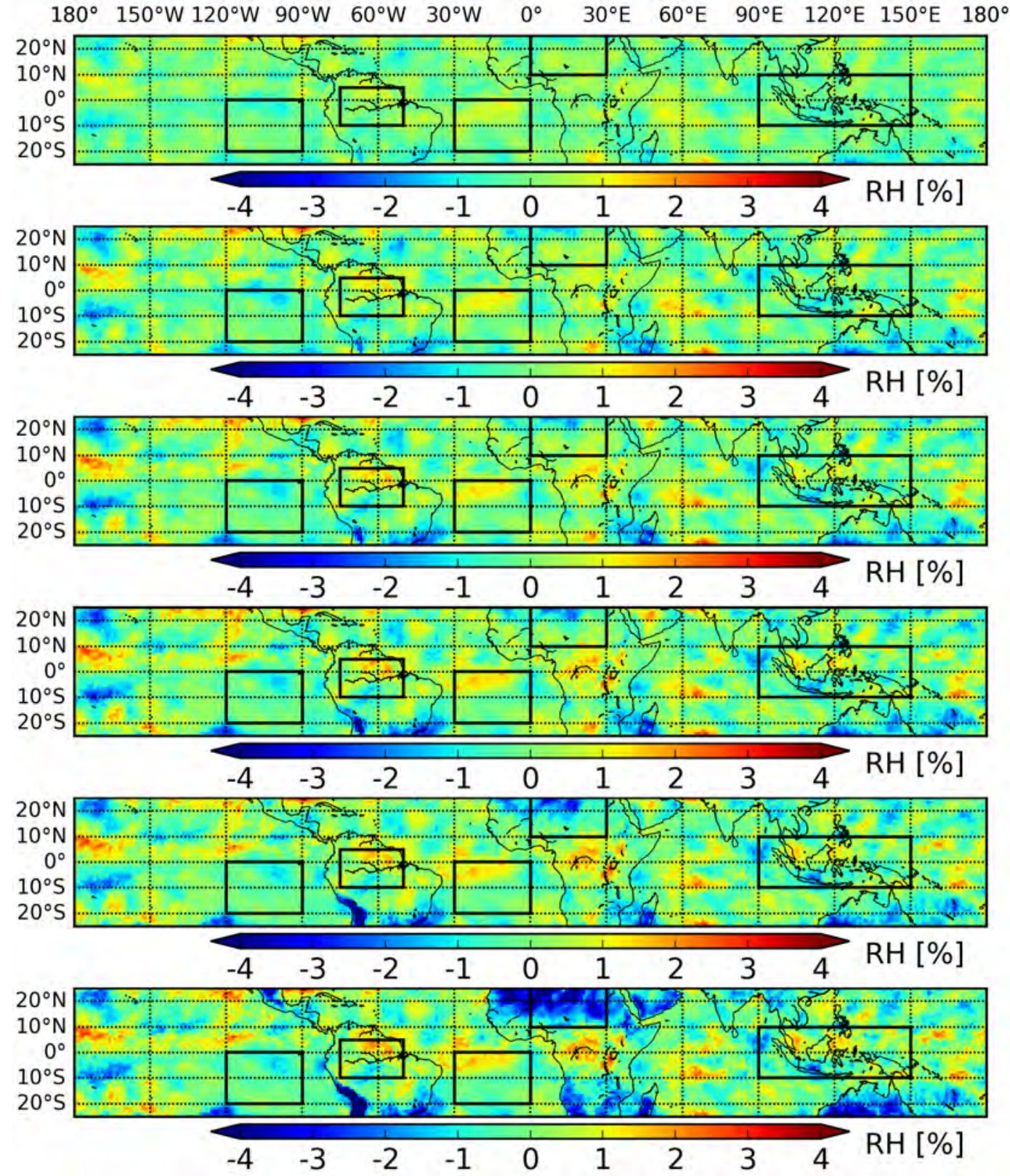

Figure 4. Mean difference of daily average of $\mathrm{RH}_{L}$ calculated using only data from 01:30/13:30 local time and the daily average calculated using all hourly data. Plots from top to bottom are for SAPHIR channels 1-6, respectively. 

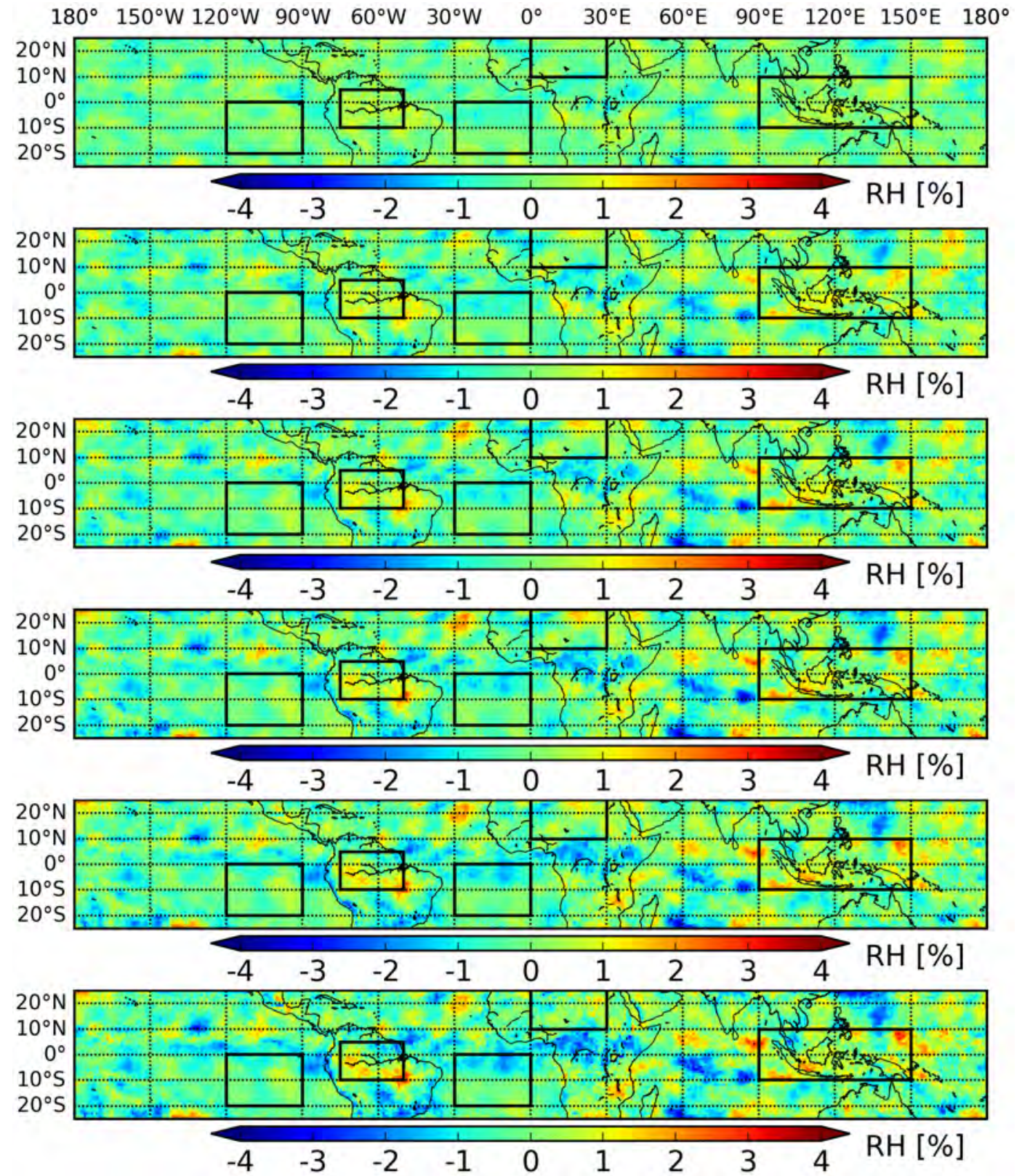

Figure 5. Mean difference of daily average of $\mathrm{RH}_{L}$ calculated using only data from 09:30/21:30 local time and the daily average calculated using all hourly data. Plots from top to bottom are for SAPHIR channels 1-6, respectively. 


\section{RH Peak and Amplitudes}

\section{(Measurements)}

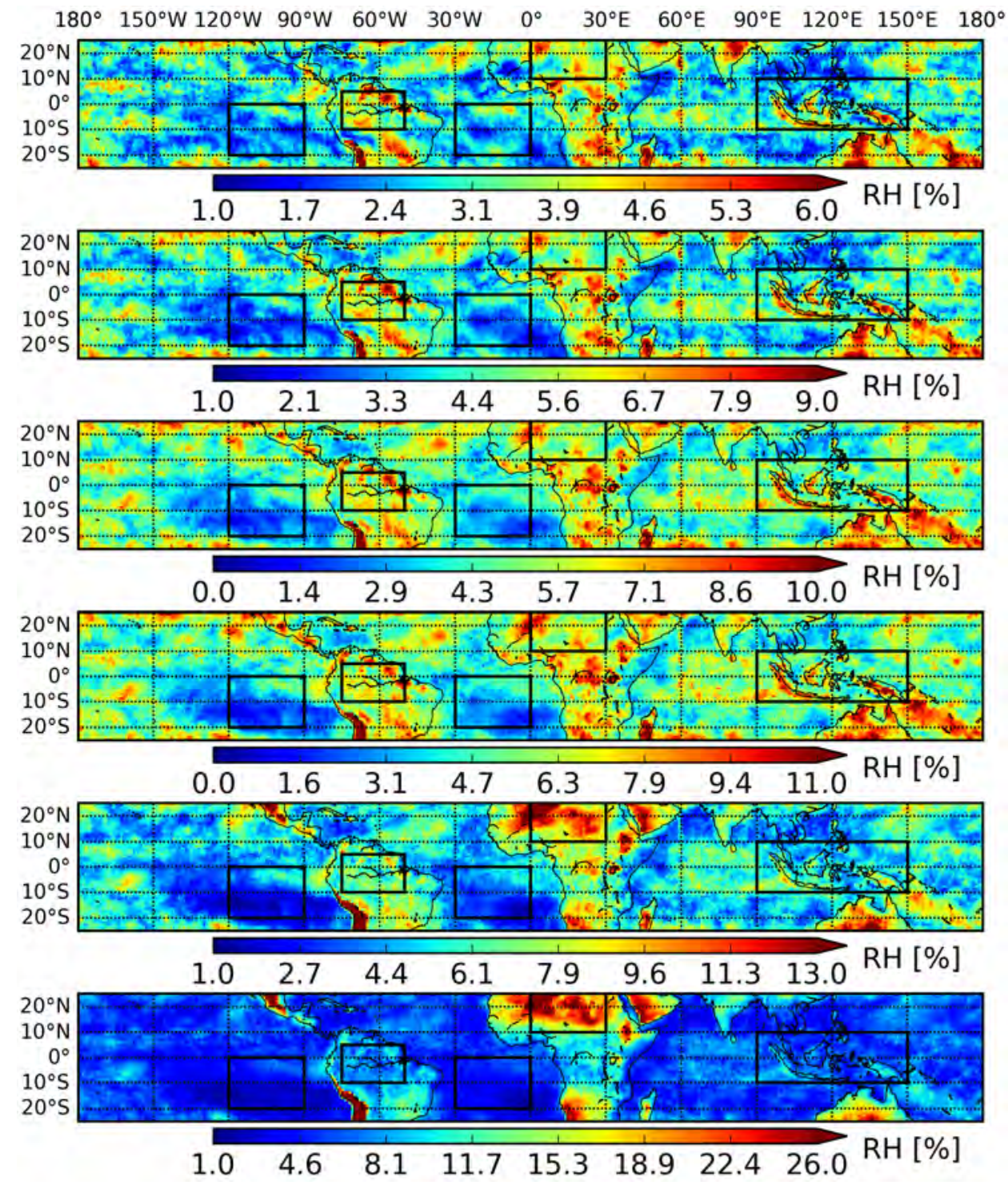

Figure 6. Spatial distribution of diurnal amplitude of tropospheric humidity over liquid (based on measurements). Plots from top to bottom are for SAPHIR channels 1-6, respectively. 


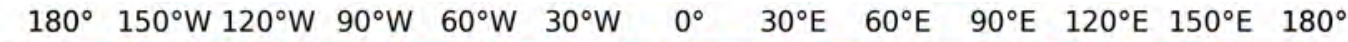
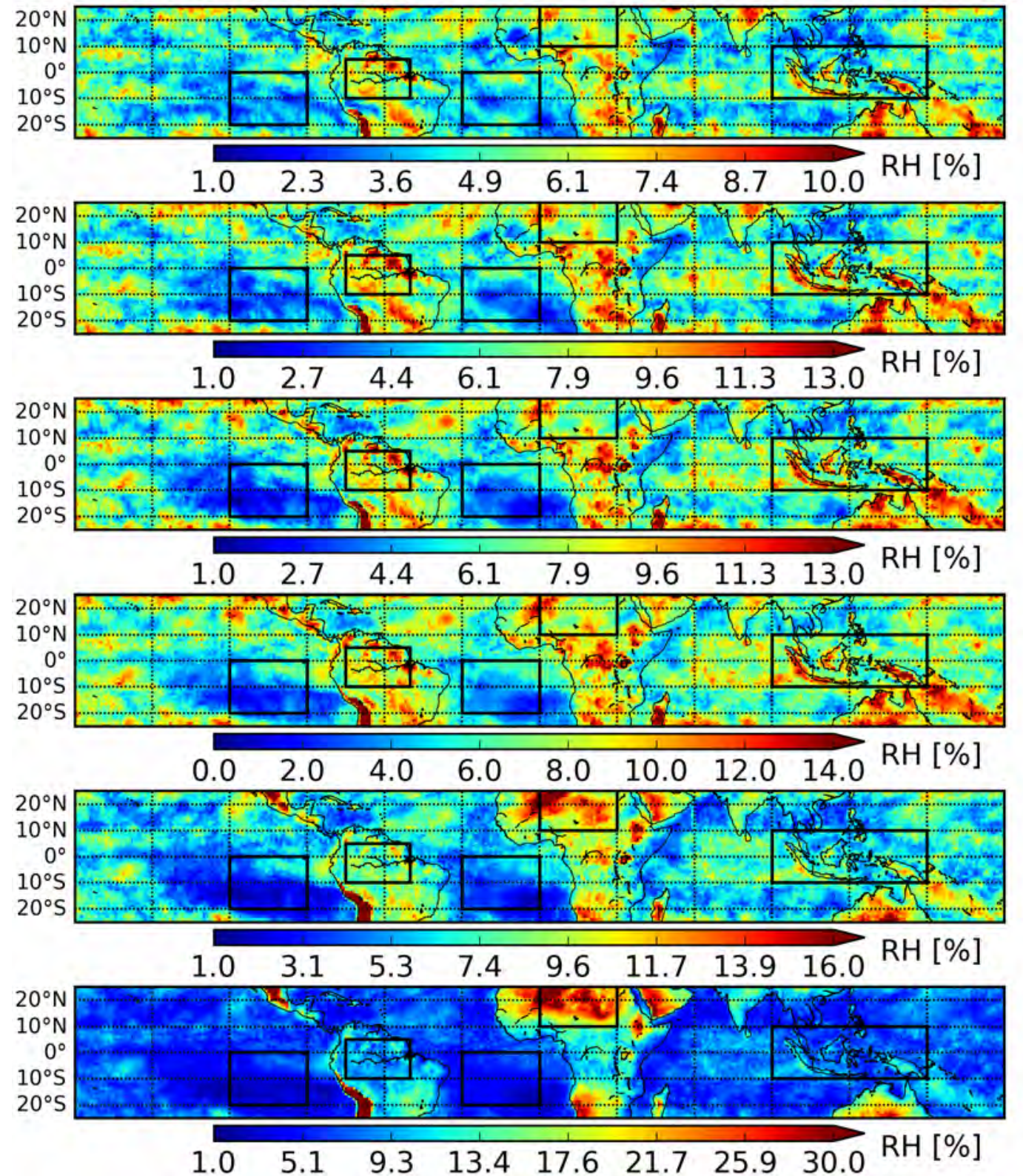

Figure 7. Spatial distribution of diurnal amplitude of tropospheric humidity over ice (based on measurements). Plots from top to bottom are for SAPHIR channels 1-6, respectively. 


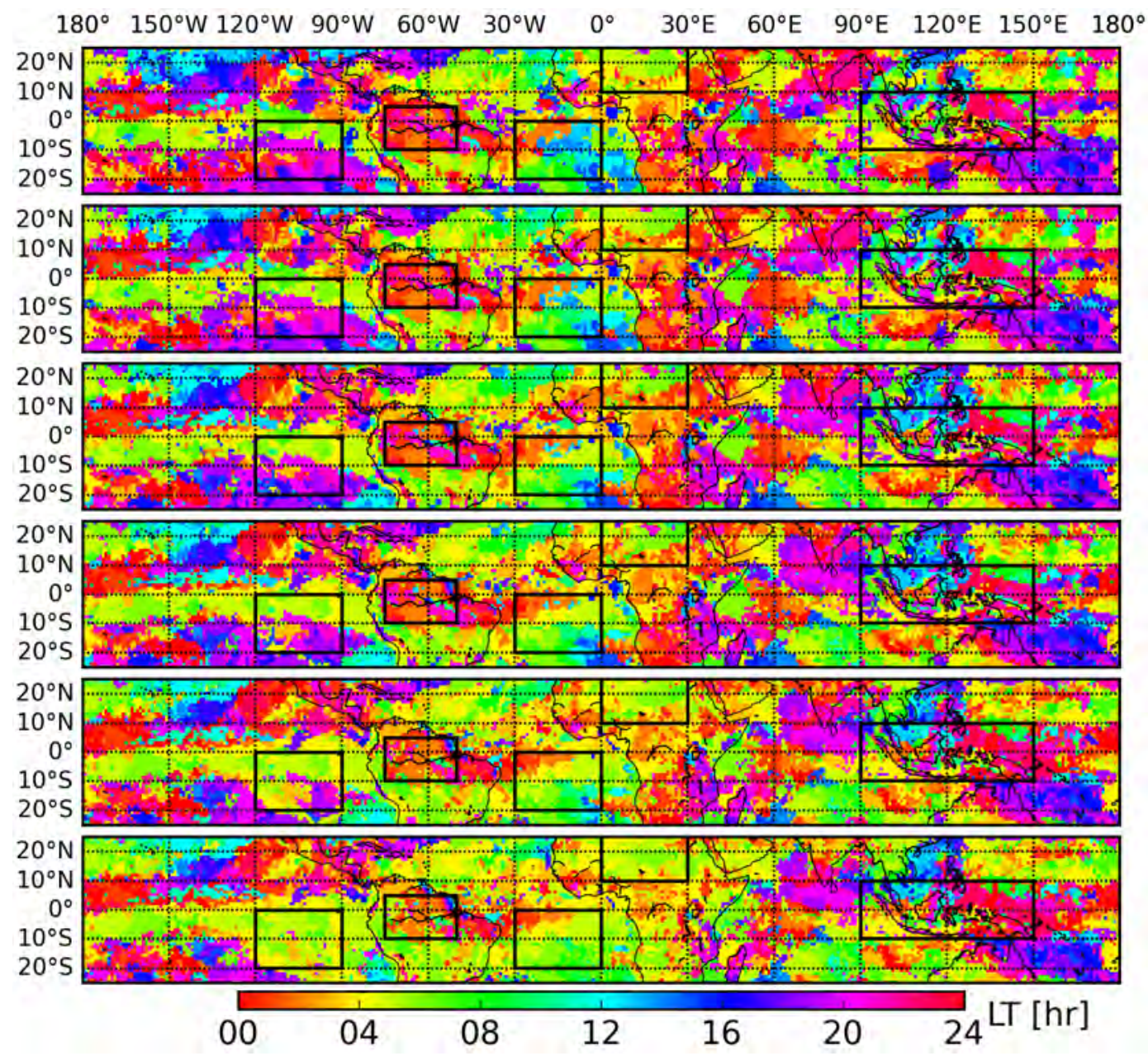

Figure 8. Diurnal peak time (based on measurements with respect to liquid) for upper to lower tropospheric channels (SAPHIR channels 1-6 from top to bottom) in local time. 


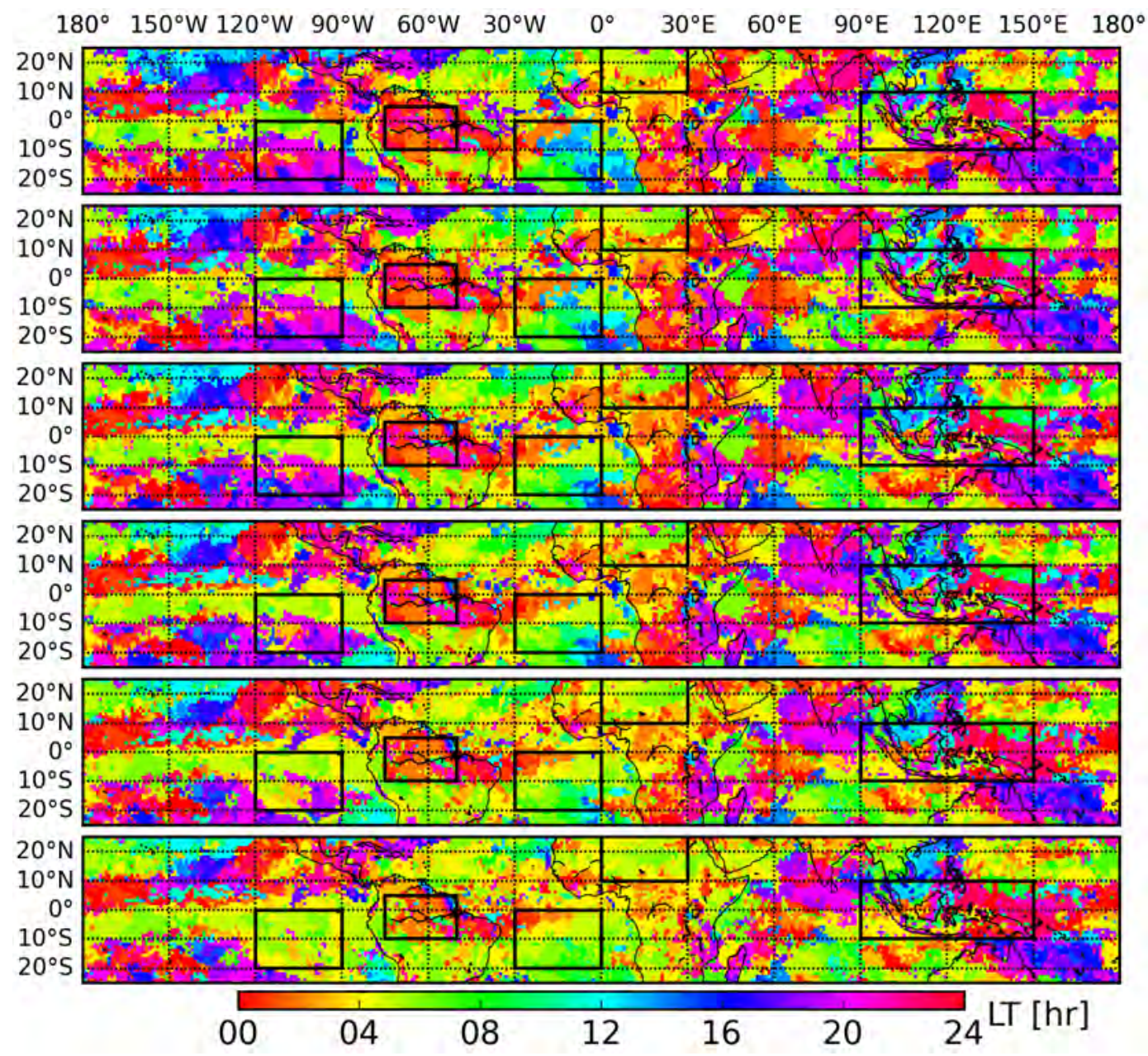

Figure 9. Diurnal peak time (based on measurements with respect to ice) for upper to lower tropospheric channels (SAPHIR channels 1-6 from top to bottom) in local time. 


\section{RH Peak and Amplitudes Derived From Fourier Series}
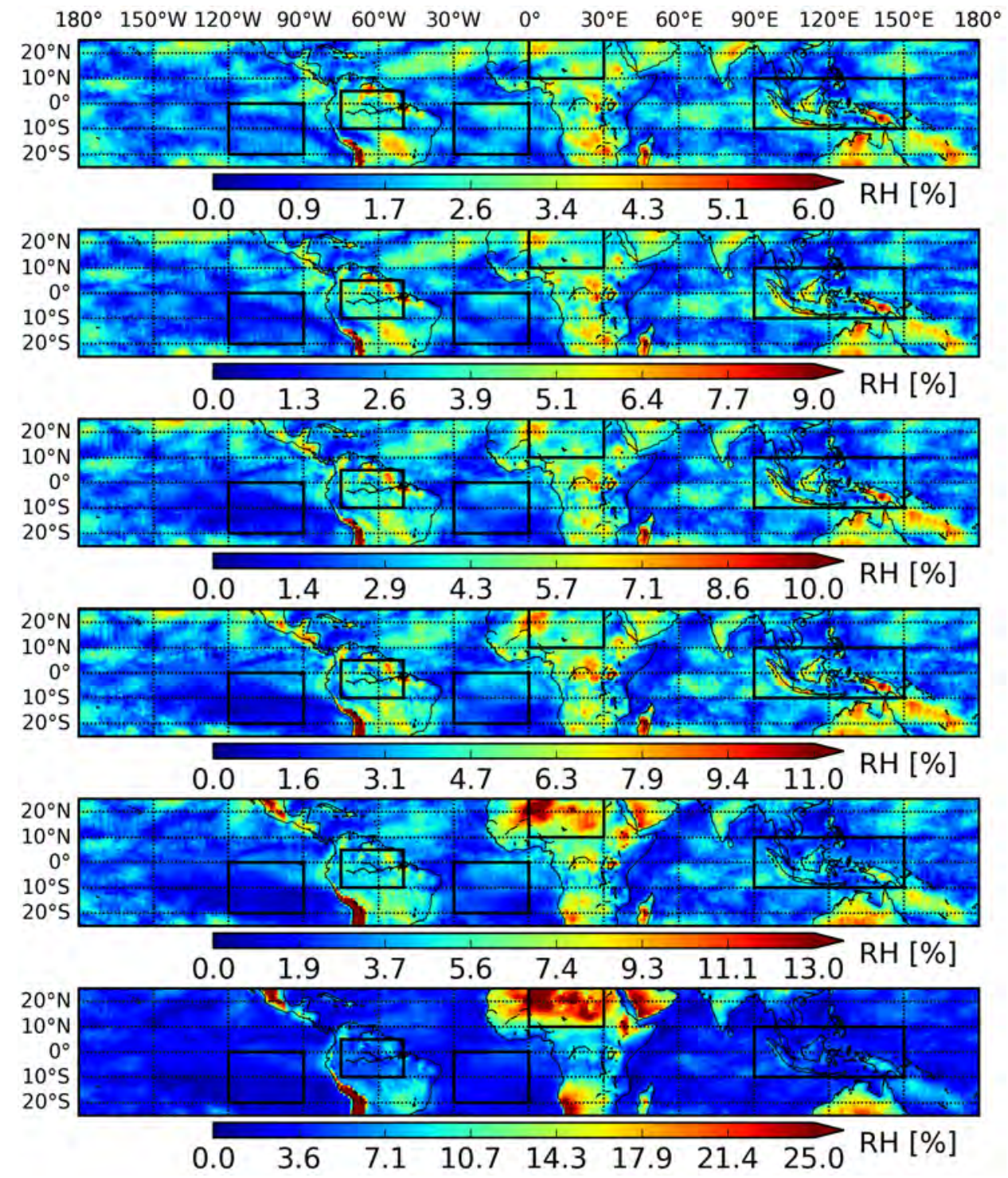

Figure 10. Spatial distribution of diurnal amplitude of tropospheric humidity over liquid (based on the Fourier series fit). Plots from top to bottom are for SAPHIR channels 1-6, respectively. 


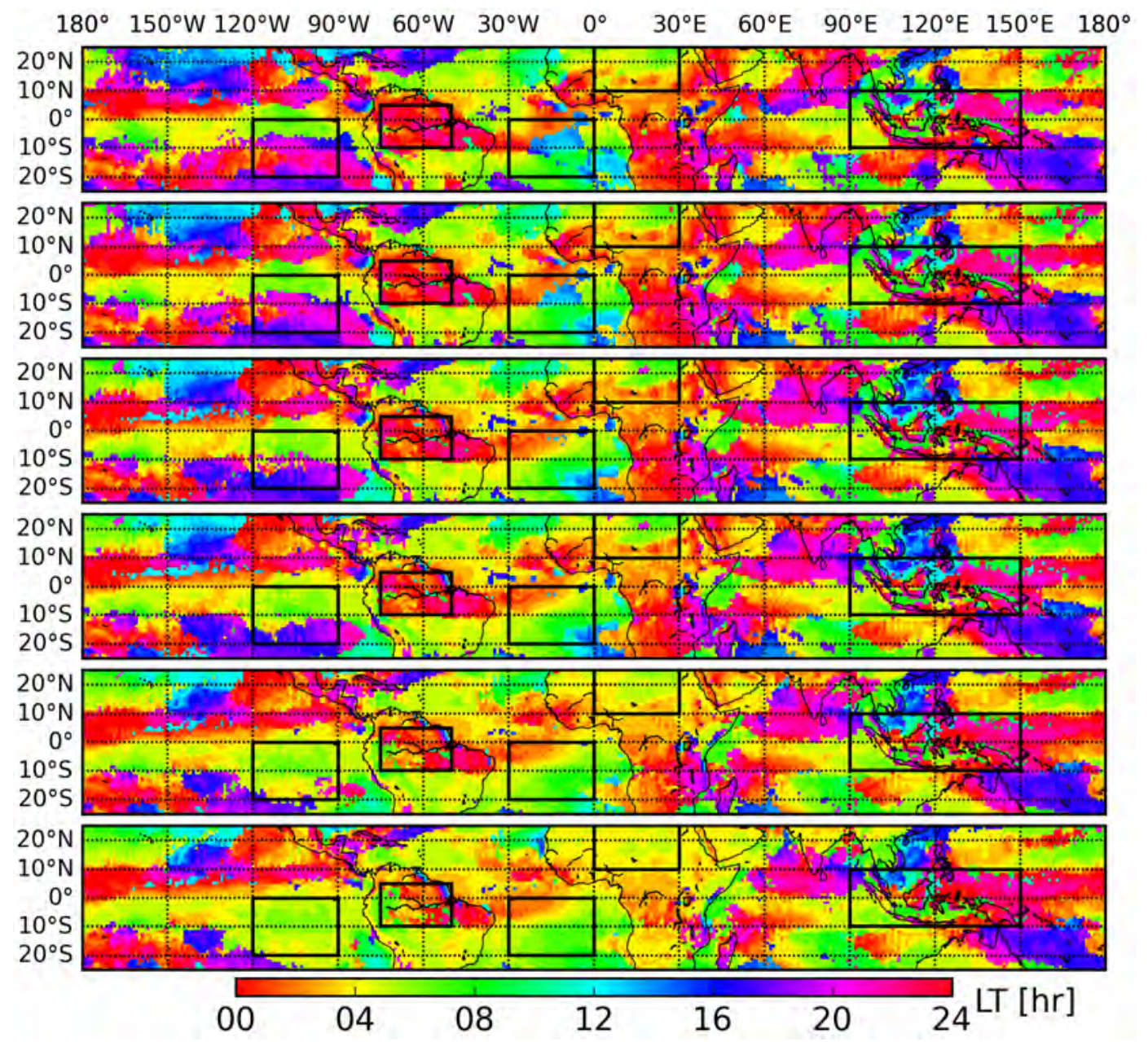

Figure 11. Diurnal peak time (with respect to liquid and based on Fourier series fit) in local time. Plots from top to bottom are for SAPHIR channels 1-6, respectively. 


\section{Fourier Series}

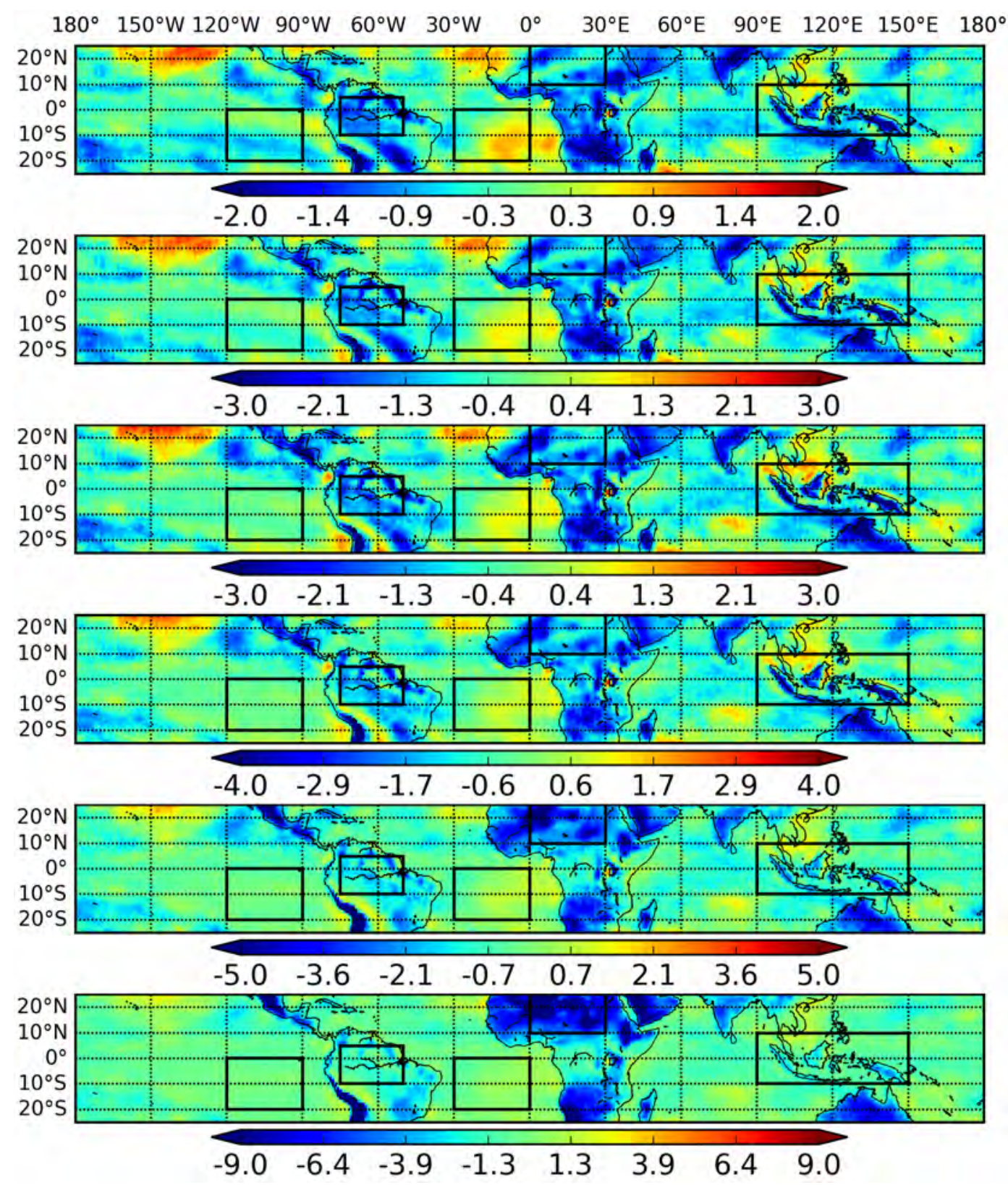

Figure 12. The coefficient $a_{1}$ (with respect to liquid) for the Fourier series fit. Plots from top to bottom are for SAPHIR channels $1-6$, respectively. 


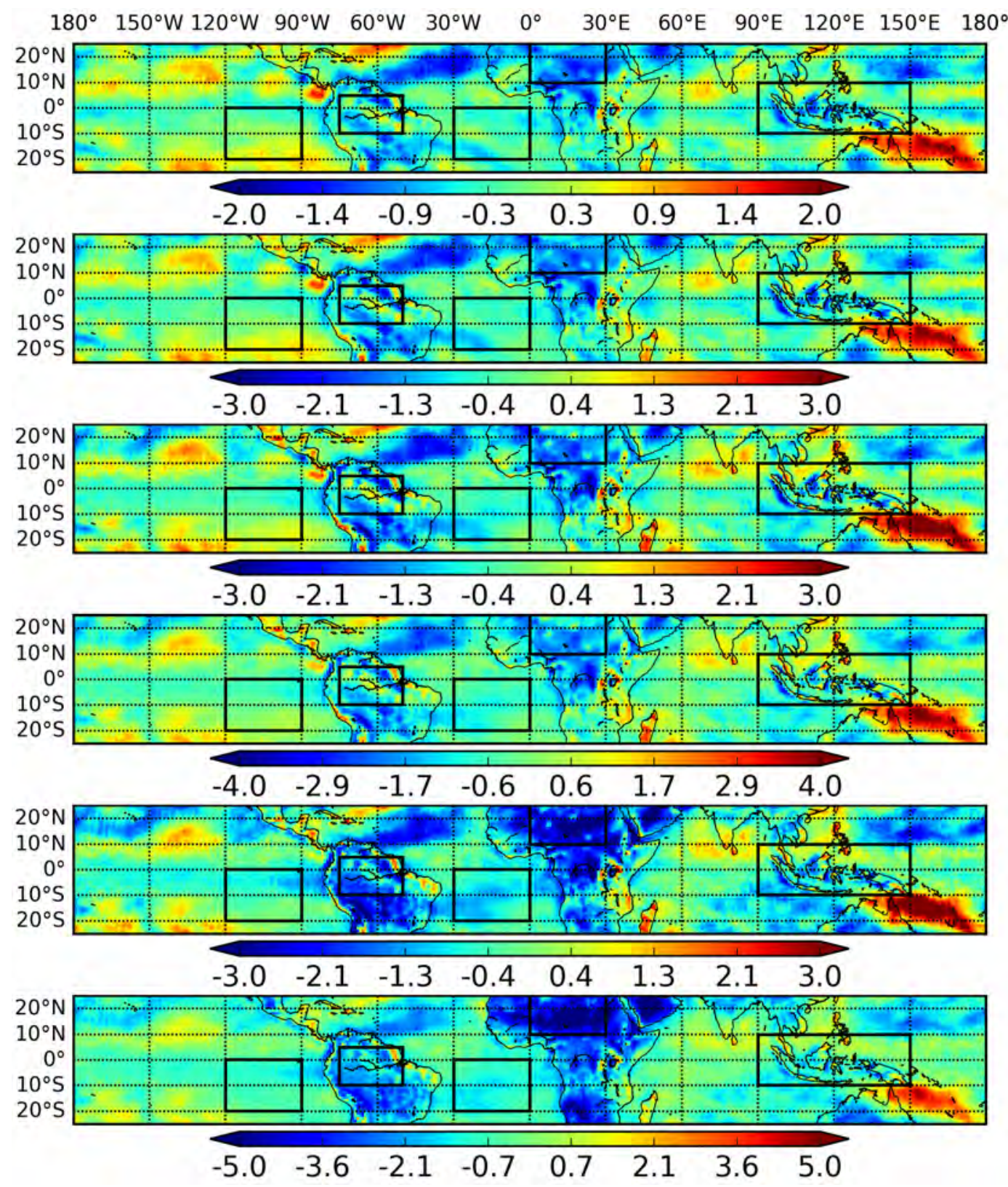

Figure 13. The coefficient $b_{1}$ (with respect to liquid) for the Fourier series fit. Plots from top to bottom are for SAPHIR channels $1-6$, respectively. 

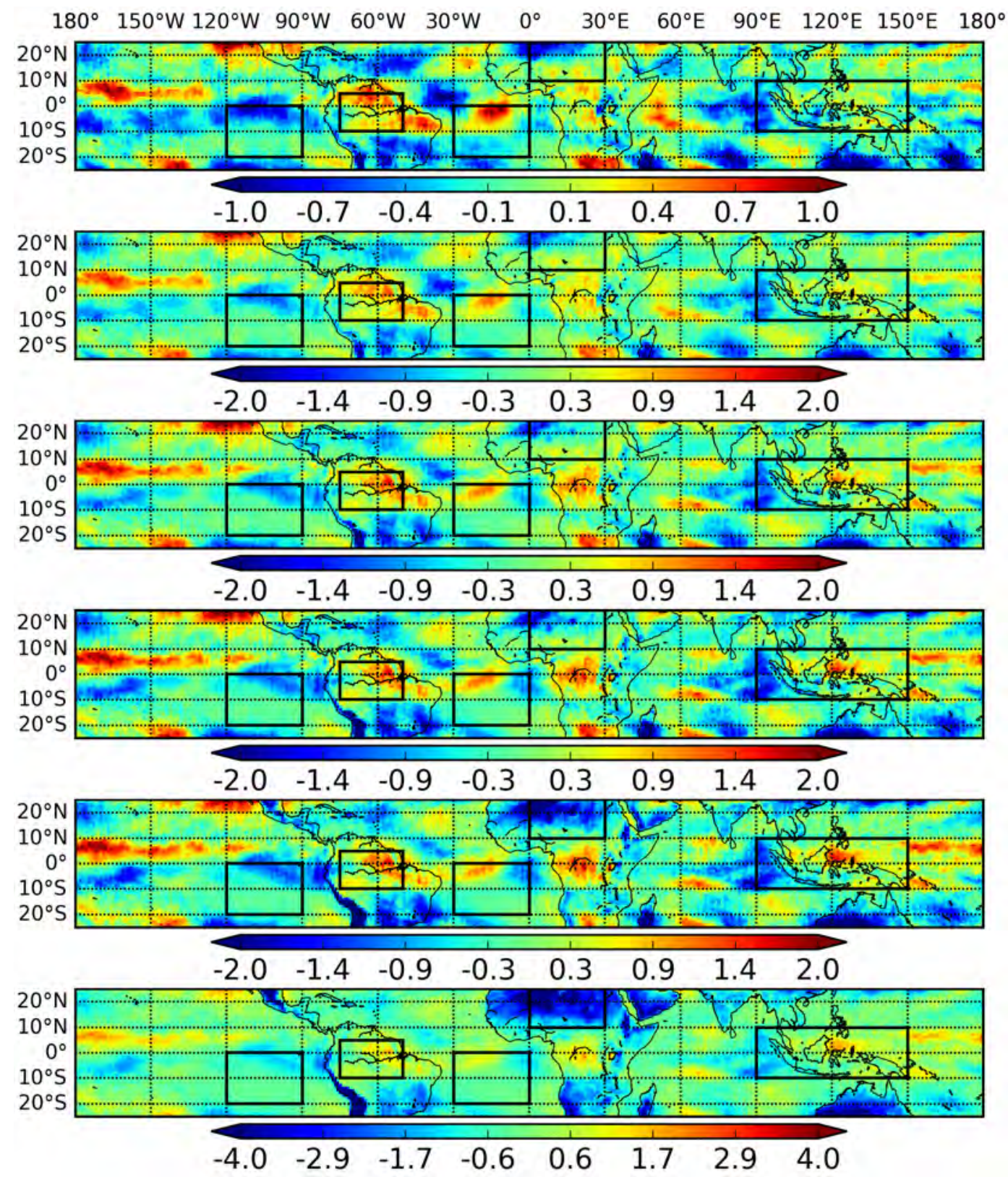

Figure 14. The coefficient $a_{2}$ (with respect to liquid) for the Fourier series fit. Plots from top to bottom are for SAPHIR channels $1-6$, respectively. 


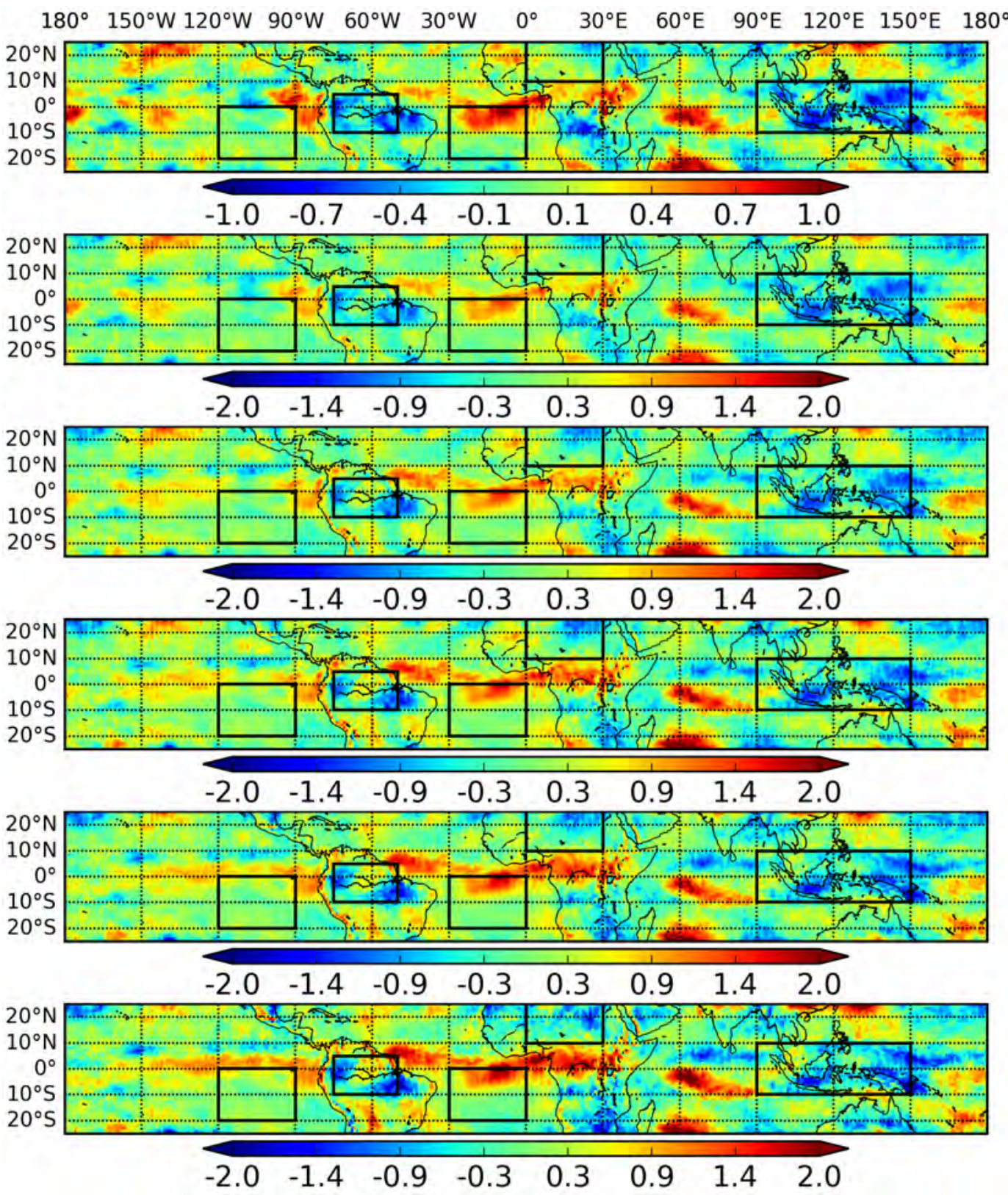

Figure 15. The coefficient $b_{2}$ (with respect to liquid) for the Fourier series fit. Plots from top to bottom are for SAPHIR channels $1-6$, respectively. 


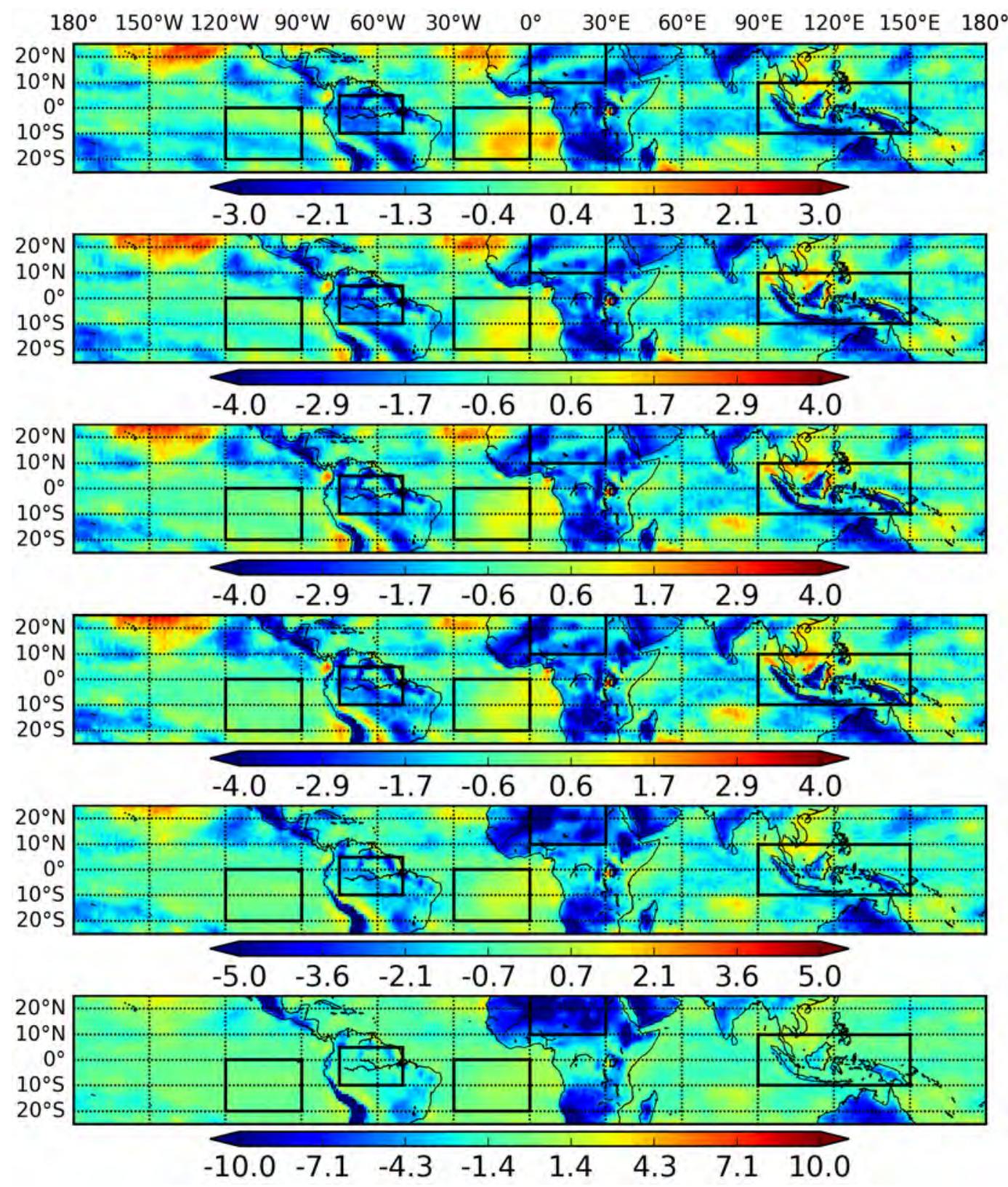

Figure 16. The coefficient $a_{1}$ (with respect to ice) for the Fourier series fit. Plots from top to bottom are for SAPHIR channels $1-6$, respectively. 


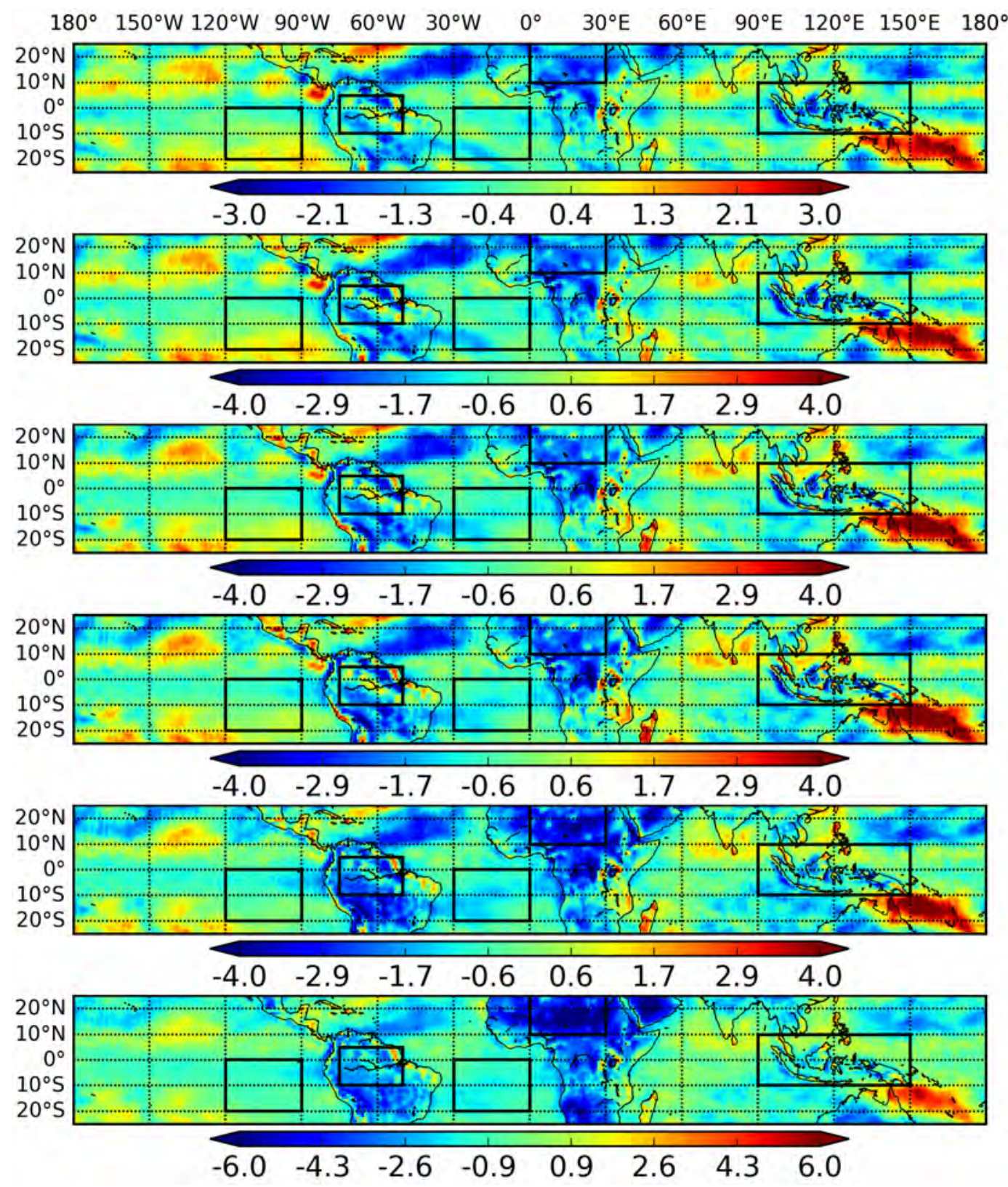

Figure 17. The coefficient $b_{1}$ (with respect to ice) for the Fourier series fit. Plots from top to bottom are for SAPHIR channels $1-6$, respectively. 

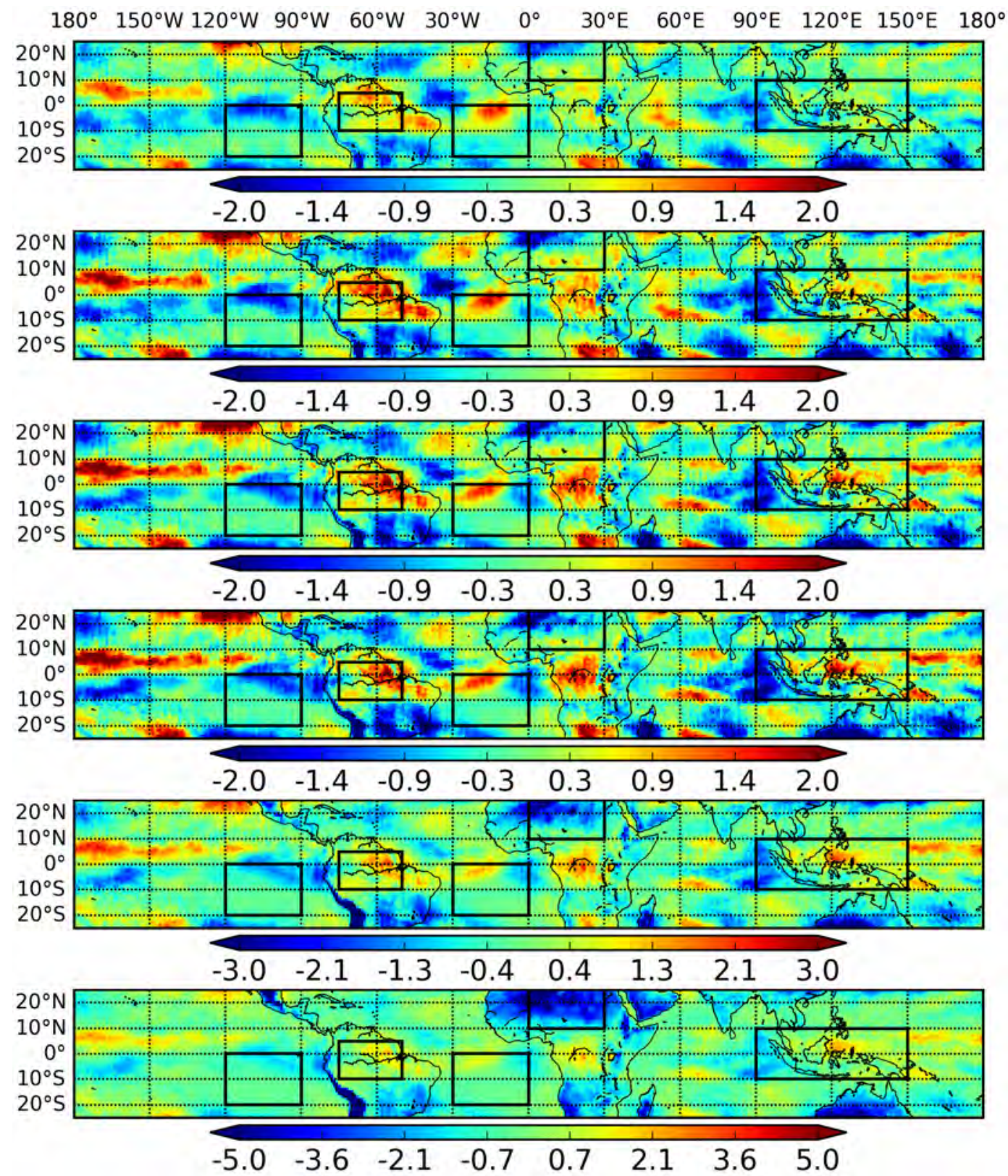

Figure 18. The coefficient $b_{2}$ (with respect to ice) for the Fourier series fit. Plots from top to bottom are for SAPHIR channels $1-6$, respectively. 


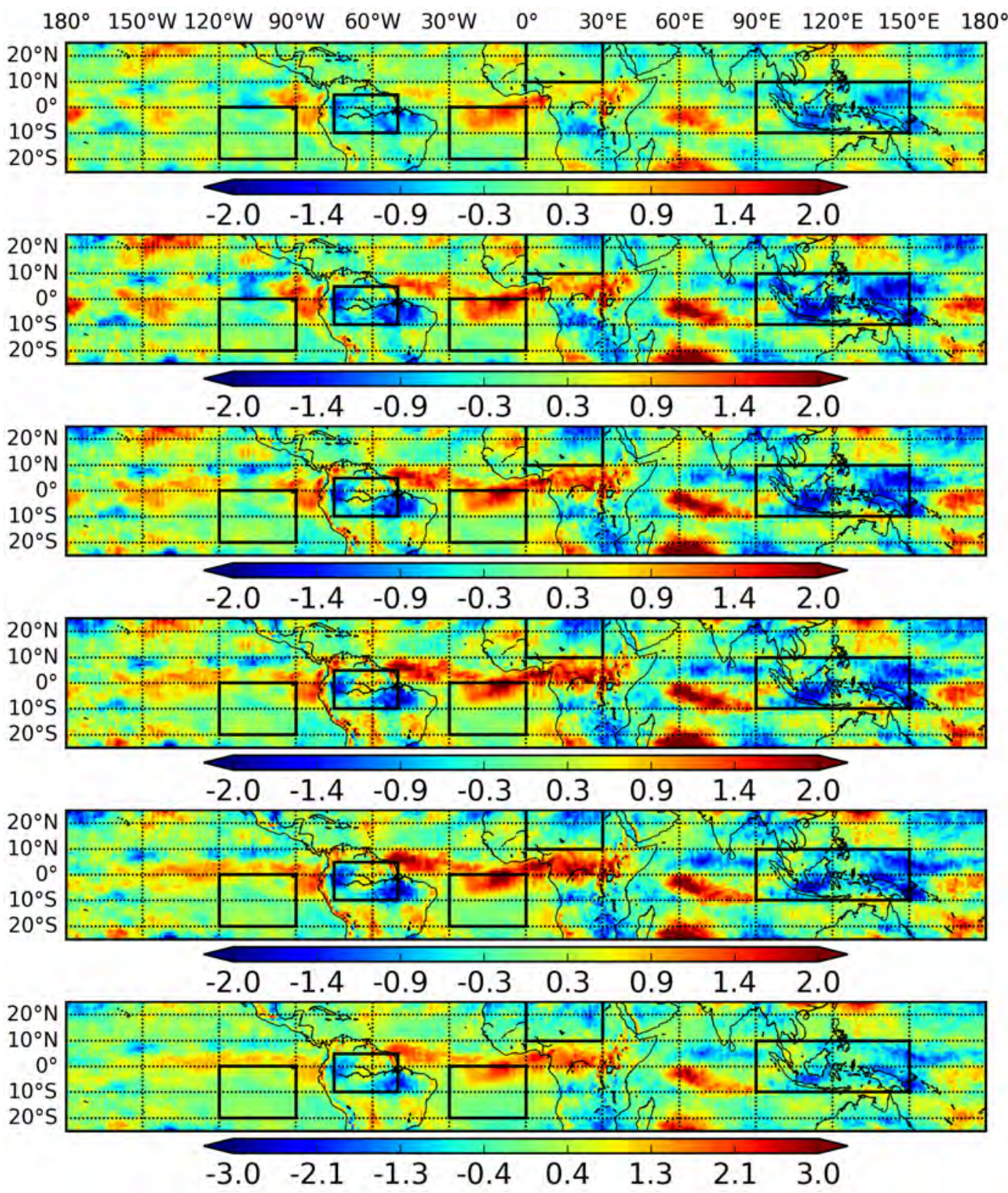

Figure 19. The coefficient $b_{2}$ (with respect to ice) for the Fourier series fit. Plots from top to bottom are for SAPHIR channels $1-6$, respectively. 


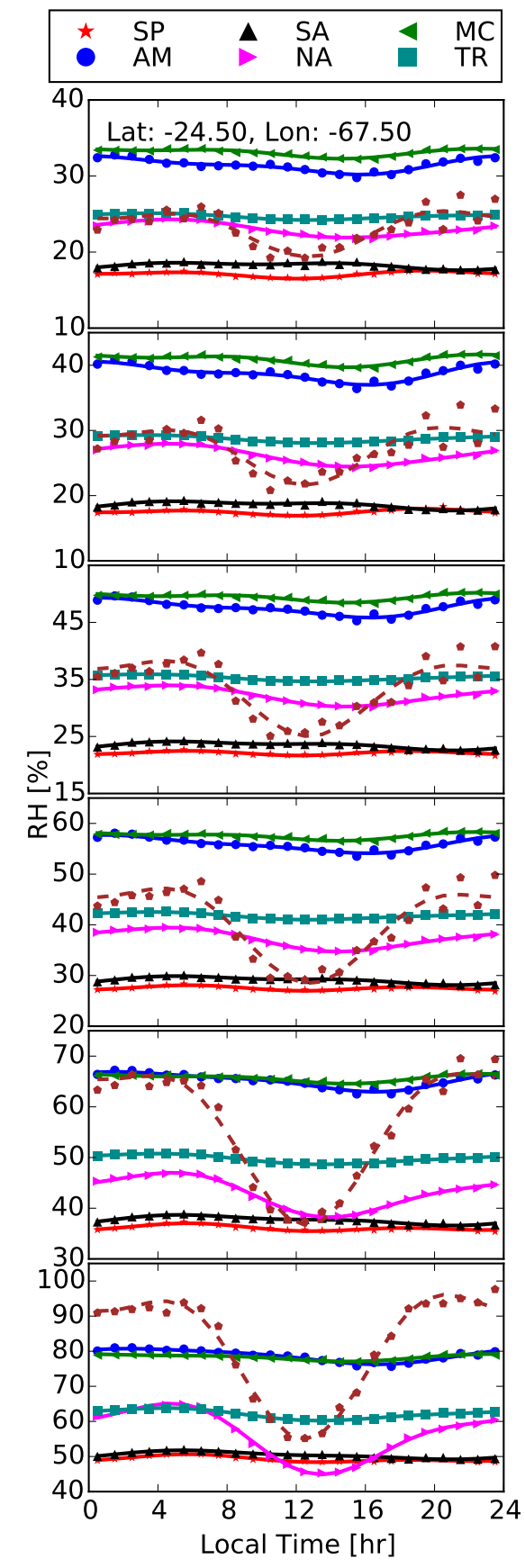

Figure 20. Diurnal cycle of layer-averaged $\mathrm{RH}_{L}$ as well as Fourier series fit for the selected regions. Plots from top to bottom are for SAPHIR channels 1-6, respectively. 

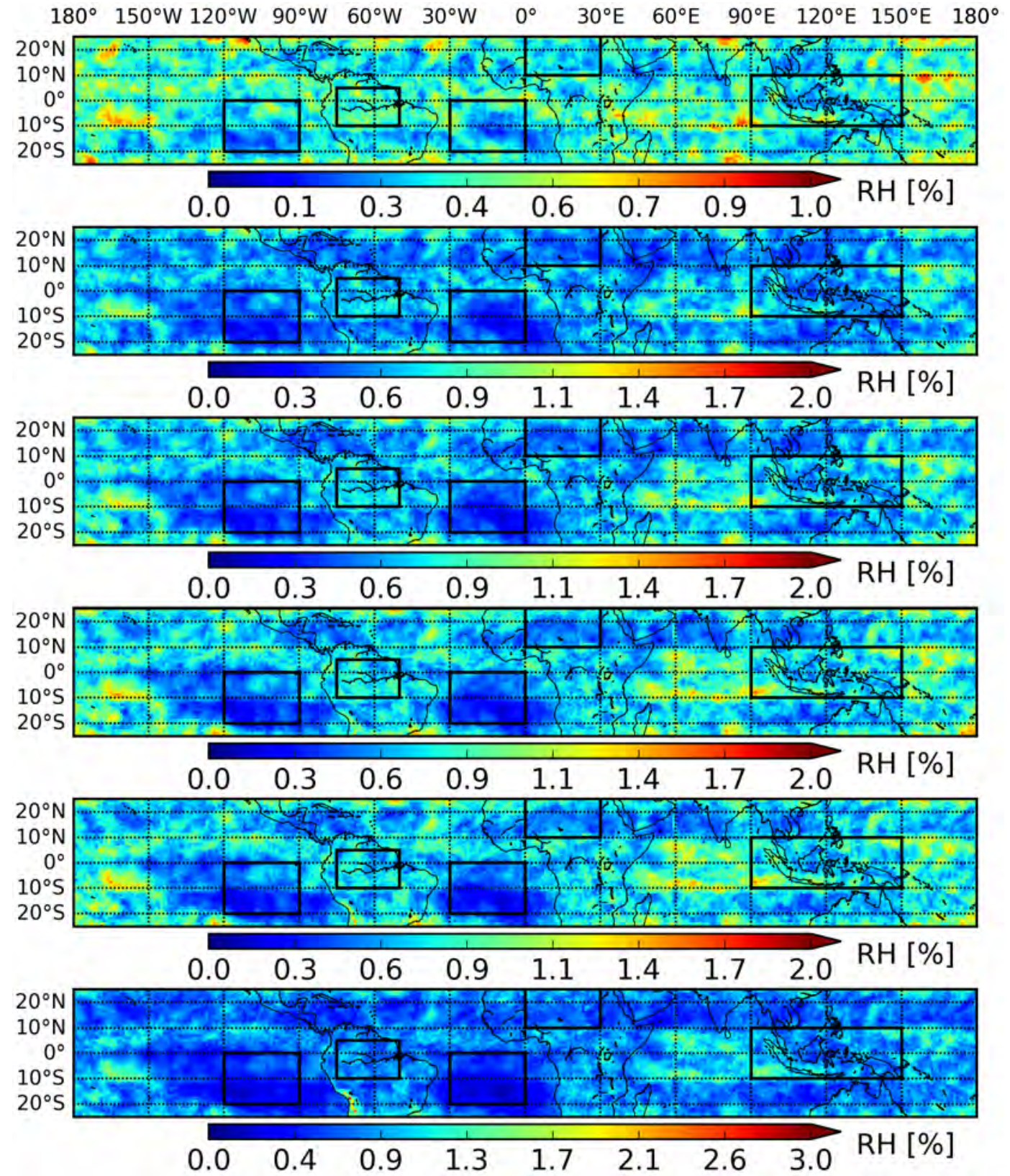

Figure 21. Mean absolute difference (with respect to liquid) between measurements and the fit for Fourier series. Plots from top to bottom are for SAPHIR channels 1-6, respectively. 


\section{Distribution Functions}

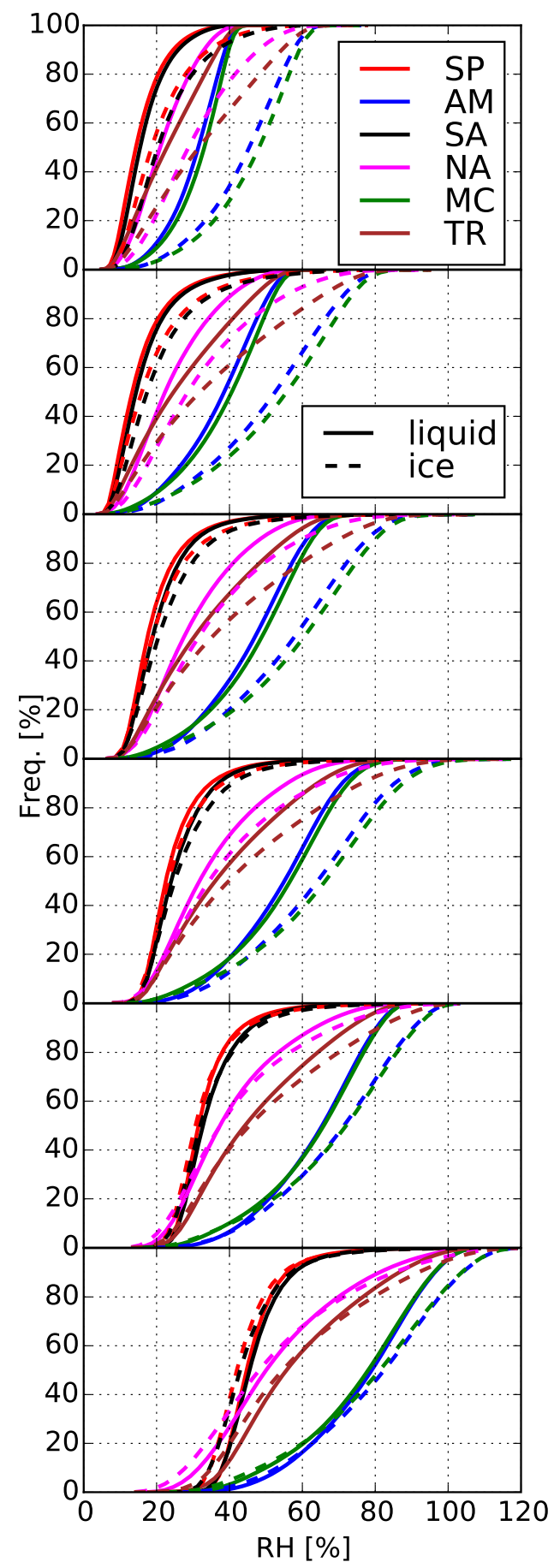

Figure 22. Cumulative probability distribution functions for relative humidity. Plots from top to bottom are for SAPHIR channels 1-6, respectively. 